is potentially a huge disparity between nurses practising as nurse practitioners. Employers may equally be confused and unclear as to what to expect from the nurses. Nurse practitioners themselves are frustrated at constantly needing to explain who they are and what they do to patients and colleagues, and are distressed at the potential for damage and harm in this situation.

The Nurse Practitioner Association of the Royal College of Nursing have been working to rectify this situation over the past decade. The Nursing and Midwifery Council have agreed competencies and educational levels for nurse practitioners but are unable to enforce this until the government agrees the legislation. In most other countries where nurse practitioners practice there is a regulated title that allows a recognised level of education and training and would allow re-accreditation.

This situation affects research as well as practice in terms of transferability of studies as there is nothing standardised about either the title or the training of nurse practitioners. Other practices could not therefore, assume that their nurse practitioner was equally qualified or prepared to do the same work.

\section{Wendy Fairhurst,}

Nurse practitioner/Nurse partner,

Marus Bridge Practice, Wigan.

E-mail: fairhurstwendy@yahoo.co.uk

\section{REFERENCES}

1. Edwards M, Bobb C, Robinson SI. Nurse practitioner management of acute in-hours home-visit or assessment requests: a pilot study. Br J Gen Pract 2009; 59(558): 7-11.

2. Horrocks S, Anderson E, Salisbury C. Systematic review of whether nurse practitioners working in primary care can provide equivalent care to doctors. BMJ 2002; 324(7341): 819-823.

DOI: 10.3399/bjgp09X420996

\section{Authors' response}

We would echo Wendy Fairhurst's frustration with the lack of consensus definition of a 'nurse practitioner', and the myriad different qualifications and levels of experience which (generally self-styled) nurse practitioners variously demonstrate.
Indeed, this issue caused the first author (ME) some initial confusion when this study was conceived. Space precluded a detailed description of the qualifications and experience of the single nurse practitioner (CB) employed in our study, and the lack of any established criteria essentially meant that, for us to offer a definition of nurse practitioner as Fairhust suggests, would involve listing CB's entire four-page CV - which further reinforces Fairhurst's point (a CV is however, available on request). Nurse practitioners find themselves in a situation analogous to that of GPs, and their predecessors the surgeon-apothecaries, in the first half of the 18th century: facing competition from less qualified and less experienced colleagues who were entitled, under the 'laissez-faire' politics of the day, to bill themselves as professional equals. Half a century of lobbying and the formation of many GP associations (mostly short-lived, although one survives today as the British Medical Association) culminated in the Medical Act of 1858, establishing unified standards of training and qualifications for all doctors. We hope that it will not take another 50 years to establish a similarly unified and recognised curriculum for nurse practitioner training.

\section{Martin Edwards,}

GP, Jenner Practice, 201 Stanstead Road, London, SE23 $1 \mathrm{HU}$.

E-mail: martin.edwards@ucl.ac.uk

\section{Carol Bobb,}

Nurse practitioner, Fairhill Medical Practice, Kingston University Health Centre, Surrey.

DOI: 10.3399/bjgp09X421003

\section{Clinical researchers}

I am glad I seem to have initiated a debate about practice-based research and its publication in the BJGP, but find myself accused as thoughtless by a guru and ignored by College prelates who responded to his blast concerning his own agenda.

My initial letter ${ }^{1}$ was to support lan McWhinney's concern about the lack of publication of research on clinical insight or discovery by GPs. The Editor of the Annals of Family Medicine responded immediately by inviting submissions on 'emergent discoveries based on careful clinical observation' from its readership. The Editor of the BJGP has made no such offer. Julian Tudor Hart presumes that I (and presumably McWhinney) have not thought deeply enough about the issue but also urges us all to have an unshakeable faith in the Editors' wisdom and insight in the matter. ${ }^{2} \mathrm{He}$ has no doubt that if good clinical research by GPs in their own practices were submitted, the Editor would be delighted to publish it.

There the matter might have rested had his rambling tirade not been responded to by three College representatives, ${ }^{3}$ and they demonstrate why I was probably correct to be concerned. It seems that clinical researchers in general practice are indulging in 'occupational therapy for doctors' and they declare, seemingly on behalf of the College, their belief that the days of the 'gentleman amateur' working to produce research in a general practice 'cottage industry' are now over. It seems that GPs now have to be members of research networks before they can be researchers. Presumably, it will only be these fortunate enough to rise to the top of these pyramid schemes who will qualify for the RCGP Discovery Prize for original research in general practice.

I may not have thought deeply enough about all this but it was my impression that the discipline of general practice was about the delivery of primary, personal, and continuing care of individuals, families, and practice populations. It is therefore, imperative that research is carried out by individual GPs in their own practices, and for three College prelates to suggest otherwise is outrageous. Of course research networks are important and we must encourage the academic activities of academic departments, but these will only produce abstractions and generalisations about general practice, which are only one side of the story. As McWhinney pointed out, quoting from James, we also need 'an acquaintance 
with particulars', ${ }^{4}$ which can only come from practice-based research.

\section{John Campbell Murdoch,}

Professor, School of Primary, Aboriginal and Rural, Health Care, Rural Clinical School, St John of God Medical Centre, PO Box 412, Bunbury WA 6230, Australia.

E-mail: Campbell.murdoch@uwa.edu.au

\section{REFERENCES}

1. Murdoch JC. The end of practice-based research? $\mathrm{Br} J$ Gen Pract 2009; 59(558): 52 .

2. Tudor Hart J. Clinical research by GPs in their own practices. Br J Gen Pract 2009; 59(560): 214-215.

3. Mathers N, Howe A, Field S. Clinical research by GPs in their own practices. BrJ Gen Pract 2009; 59(561): 296-297.

4. McWhinney IR. 'An acquaintance with particulars...' Fam Med 1989; 21(4): 296-298.

DOI: 10.3399/bjgp09X421012

\section{Medical waste}

With the Chancellor's budget having been recently announced amidst the ongoing global economic downturn, I thought it an opportune moment to highlight to readers the current situation of pharmaceutical wastage in the NHS. Currently undergoing a placement in public health I was privy to witness one of many 'spot inspections' of a vehicle that was in-transit to the local waste disposal site having collected all discarded medications from a local pharmacy. The contents of the van were astounding. Inside were over 30 plastic sacs containing stacks of unopened blister packs, boxes of unused laxatives, and endless tubs of emollients, most of which were well within their expiry date. In addition, there were over a dozen large plastic tubs full of a certain wellrecognised and quite pricey supplement drink, all of which had been unused and subsequently thrown out. At present, the current cost of medicines wastage in the West Midlands stands at an impressive $£ 32$ million every year, ${ }^{1}$ while back in 2006 it was estimated that the cost of returned and unused medicines in total throughout the UK was anything up to $£ 75$ million per year. ${ }^{2}$ Despite these huge figures it would appear that at grassroots level the problem remains largely unchecked and obviously some additional intervention is required in order to reduce this unnecessary and costly drain on our health service. Although the responsibility lies with all healthcare professionals it does appear a large source of wasted medicines, using that inspection as a basis, comes especially from local care homes. Due to the apparent failures in communication that are occurring, the current approach of allowing endless piles of unwanted medicines to accumulate, gather dust, and then be disregarded at the end of the month seems an unforgiveable and unsustainable way to manage the problem.

With the current economic climate, as well as ever-increasing demands on evertightening NHS budgets, it would seem prudent to emphasise that efficient medication reviews by GPs, pharmacists, and non-medical prescribers could at least, on our parts, help stem this ruinous haemorrhage of funds from our local PCTs.

\section{James Crossingham,}

GP ST1 trainee, Public Health, Jubilee House, Walsall.

Email: james.crossingham@walsall.nhs.uk

\section{REFERENCES}

1. West Midlands NHS. Medicines Waste Campaign Page. http://www.medicinewastewestmidlands.com/wmpages/wmcontact.htm (accessed 15 May 2009).

2. British Pharmaceutical Conference. Britain's $\mathfrak{E} 75$ million drug waste. [News] http://www.rpsgb.org.uk/pdfs/pr060904-6095.pdf (accessed 15 May 2009).

DOI: 10.3399/bjgp09X421021

\section{Osteoporosis guideline}

Jonathan Bayly is correct in reminding us that the guidance from the National Osteoporosis Guidelines Group (NOGG) should be critically appraised. ${ }^{1}$ It is not however, a rival to NICE but seeks to provide a user-friendly guideline to include men, steroid-induced osteoporosis, the newer bisphosphonates, recombinant human parathyroid hormone, and also to include the World Health Organisation Fracture Risk Assessment Tool (FRAX'MM).
Since NOGG is web-based it is relatively easy to keep it constantly updated.

Guidelines are dependant upon published studies. These studies, which are expensive, at present recruit patients that are at very high risk of developing the endpoint in question, but are otherwise relatively uncomplicated. The studies are comparatively short and are not powered to study the long-term side effects.

These relatively short-term controlled studies are then extrapolated to the real world of free roaming patients, with comorbidities, co-prescribing with its associated drug interactions, and poor medication compliance. These patients may also be in a different age range to those in the randomised controlled studies. Further studies are required after the pivotal randomised controlled studies and granting of a product licence, to study medications in the true environments in which they are used.

However, because we do not have the best data this must not be an excuse to do nothing. 'The care gap is wide and not getting any narrower." We now have the opportunity with a user-friendly tool, to focus on the end organ damage of fracture remembering that osteoporosis is a very important risk factor, but nevertheless, only a surrogate marker.

\section{Alun Cooper,}

Bridge Medical Centre, Wassand Close, Three Bridges Road, Crawley RH10 1LL. Email: alun.cooper@gp-H82047.nhs.uk

\section{Conflict of interest}

I am a member of NOGG-the National Osteoporosis Guideline Group.

\section{REFERENCE}

1. Bayly J. A fractured service: will NOGG mend it? $\mathrm{Br} \mathrm{J}$ Gen Pract 2009; 59(562): 371.

DOI: 10.3399/bjgp09X421030

\section{CAM}

I would be interested to hear Edzard Ernst's observations on Fiona Barlow and George Lewith's 'The Ethics of Complementary Therapy Research 